\title{
Control of spatial effects due to neighboring palms in coconut (Cocos nucifera) experiments
}

\author{
T. S. G. Peiris ${ }^{1}$, P. Waidayaratne ${ }^{2}$, S. Samita ${ }^{3}$ and R. O. Thattil ${ }^{3}$
}

\begin{abstract}
The RCBD is the most robust design for field experimentations in coconut. In this study the effect of neighboring palms to control local variation in field experiments of coconut was evaluated using two long-term coconut trials. Four types of spatial models are suggested to consider the spatial effect due to neighboring palms and the use of such models is illustrated using two long-term field experiments. When data were analyzed separately by years or using repeated measures analysis, significant percentage reduction of $\mathrm{CV}$ was observed in all four spatial models relative to the RCBD model without covariates as well as pre-treat data as covariate irrespective of the experiment. Inclusion of the mean of two neighbouring palms in N-S or E-W direction as a covariate was clearly superior to the RCBD without covariate as well as pre-data as covariate when data were analyzed separately by years. Inclusion of the mean of four neighbouring palms in N-S and E-W direction as a covariate was superior to repeated measures analysis in reducing local variation, irrespective of experiments. It is recommended to include effect due to neighbouring palms when analyzing field experiments in coconut. The methodology can be applied to other tree crop experiments as well.
\end{abstract}

Key words: Coconut, covariate, neighbouring adjustment, RCBD, repeated analysis, spatial effect.

\footnotetext{
${ }^{1}$ Mathematics Department, University of Moratuwa, Katubedha, Sri Lanka (email: sarathp@uom.lk)

${ }^{2}$ Biometry Division, Coconut Research Institute, Lunuwila 51160, Sri Lanka

${ }^{3}$ Department of Crop Science, Faculty of Agriculture, University of Peradeniya, Peradeniya, Sri Lanka
} 


\section{Introduction}

Coconut is a perennial tree crop of the lowland humid tropics, which is popularly referred to as "tree of life", indicating its great importance for humans and the environment. In Sri Lanka it is a crop of great economic importance as a source of export earning and as a food source. A coconut palm generally produces an inflorescence at the rate of nearly one per month, if water, light and nutrients conditions are favorable. Plant spacing has direct effect on the yield as greatest concentration of roots is found in the top $1 \mathrm{~m}$ of soil and within a radius of $2 \mathrm{~m}$ from the bole (Liyanage, 1999). The recommended plant density in coconut is 160 palms per hectare for square system $(7.9 \mathrm{~m} \times 7.9 \mathrm{~m})$ and $180 \mathrm{palms}$ per hectare for triangular system $(8 \mathrm{~m} \times 8 \mathrm{~m} \times 8 \mathrm{~m})$. The yield per palm varies between and within years and it is mainly decided by climatic, genetic and management effects (Peiris et al., 2007).

Due to the perennial growth habit of coconut, long-term field experiments are conducted to improve the productivity of coconut lands. In conducting field experiments, identifying the sources of variability and correctly using the appropriate experimental design are crucial in minimizing the local error (Pearce and Moore, 1976; Kempton and Howes, 1981; Vollmann, et al, 1995). The most robust experimental design for field experimentation in coconut is RCBD (Peiris and Thattil, 1997). The blocks are generally established based on visual observation of soil physical properties of the land or by using vegetative character/s of the coconut palms. Due to nature of genetic variability of coconut palms, it is not possible to select uniform palms within and between plots. To minimize such inherent variability, the pre treatment yield data of the palms is often used as a covariate in the analysis (Abeywardena, 1970; Peiris and Thattil, 1997).

In most of field experiments in coconut, statistical significance between treatments did not show even when the true difference is around 15 nuts per palm per year. This could happen due to not correctly identifying treatments or not correctly identifying possible sources of variability. However, spatial variability within field trials could also contribute bias to the estimation of error variance (Pearce, 1976). Nevertheless, the spatial effect due to neighboring trees is rarely taken into account in agricultural field experiments. Thus, the objective of this paper is to investigate the impact of neighboring palms on the precision of designed experiments of coconut.

\section{Materials and methods}

\section{Secondary data}

Two sets of data from field experiments conducted by the Coconut Research Institute of Sri Lanka (CRISL) were used. These data sets were purposely selected due to two types of planting systems. The response variable in both experiments was the number of fruit per palm per year. Using the conventional analysis (ie. without considering spatial effect) treatments were not significantly different in one experiment but they were in the other.

\section{Experiment 1}

The experiment was started in 1991 at Ratmalagara estate (a substation of CRISL) to determine the effect of substitution of inorganic nitrogen with organic nitrogen under three different methods. The five treatments were: $T_{1-}$ control, $\mathrm{T}_{2}$ - recommended fertilizer dosage of 3 $\mathrm{kg} / \mathrm{palm} / \mathrm{year}, \mathrm{T}_{3}-300 \mathrm{~g}$ of gliricidia lopping (in situ) $+550 \mathrm{~g}$ of SP $+1400 \mathrm{~g}$ of MOP, $\mathrm{T}_{4}-300 \mathrm{~g}$ of gliricidia lopping (outside) $+550 \mathrm{~g}$ of $\mathrm{SP}+$ $1400 \mathrm{~g}$ of MOP and $\mathrm{T}_{5}-35 \mathrm{~kg}$ of cow dung + $550 \mathrm{~g}$ of SP and 1200g of MOP. The experiment designed was RCDB with three blocks and the plots size was six. Plots were separated by guard rows, which include a single row of palms between two plots, as depicted in Fig. 1. The planting system was square. The treatments and the plots are denoted by $\mathrm{T}_{\mathrm{i}}(\mathrm{i}=1,2, \ldots, 5)$ and $\mathrm{Pj}$ $(j=1,2, \ldots, 15)$ respectively in Fig. 1 . Only the yield (nuts/palm/year) from 1991 to 1999 were used (CRI, 2000) for this study.

\section{Experiment 2}


The second experiment was also conducted at Ratamalagara estate in 1992 to evaluate three progenies of coconut crosses namely $\mathrm{V}_{1}$ - Tall $\mathrm{x}$ Tall, $\mathrm{V}_{2}$ - Tall x Dwarf Green and $\mathrm{V}_{3}$ - Tall x San Ramoan under three fertilizer levels namely $\mathrm{F}_{1}$ recommended dosage, $F_{2}$ - half of the recommended dosage and $F_{3}-1.5$ times the recommended dosage. The experiment has been conducted as a $3 \times 3$ factorial experiment using RCBD in three blocks (Fig. 2) and the plot size was 10 palms. The planting system was triangular and no guard rows had been used to separate plots. All palms had come to bearing in 1997. Thus in this experiment yield (nuts/palm/year) in 1998 and 1999 was used (CRI, 2000).

\section{Statistical analysis}

Two sets of data were analyzed separately for each year by fitting the model, $\mathrm{y}_{\mathrm{ij}}=\mu+\tau_{\mathrm{i}}+\mathrm{b}_{\mathrm{j}}+\varepsilon_{\mathrm{ij}}$ ( $y_{i j}=$ observed value of $i^{\text {th }}$ treatment and $j^{\text {th }}$ block, $\tau_{\mathrm{i}}=\mathrm{i}^{\text {th }}$ treatment effect, $\mathrm{b}_{\mathrm{j}}=\mathrm{j}^{\text {th }}$ block effect and $\varepsilon_{\mathrm{ij}}$ $=$ error $)$ without covariate as well as by taking pre-data as covariate. As pre-data were not available in both experiments, post-data of the first year were converted to use as pre-data by removing block and treatment effects as suggested by Peiris and Thattil (1997). For the purpose of comparing the efficiency, the coefficient of variation (CV) was computed for each year of the experiment. This analysis was repeated by analyzing both experiments using repeated measurement techniques. Data were analyzed using SAS software.

In order to consider the effect of neighbouring palms four types of models were introduced and data were re-analyzed according to these four types of models. The spatial position of an effective palm in a field experiment of coconut (say $\mathrm{Y}_{\mathrm{ij}}$ ) surrounded by eight other palms is shown in Fig. 3.
According to the Fig. 3 it is assumed that palms $Y_{i+1, j}, Y_{i-1 j}, Y_{i, j-1}$ and $Y_{i, j+1}$ are neighbouring palms ('neighbours') with respect to the effective palm $Y_{i j}$. . Of those $Y_{i-1, j}$ and $Y_{i+1, j}$ are called 'ends' (row wise), and $Y_{i, j-1}$ and $\mathrm{Y}_{\mathrm{i}, \mathrm{j}+1}$ 'sides'(column wise). The palms at A1, A2, A3 and A4 are called, 'corners'. It is assumed that there is no spatial effect from the corner palms on the effective palm.

Let the effect of the $\mathrm{i}^{\text {th }}$ treatment, $\mathrm{j}^{\text {th }}$ black and the grand mean be denoted by $\tau_{i}, b_{j}$ and $\mu$ respectively. As explained above, the spatial effect of neighbouring palms on the middle palm (effective palm) can be influenced by either of two neighboring palms in the E-W direction, two neighboring palms in the N-S direction, two neighboring palms in the E-W direction and N-S direction independently, or all four neighboring palms in both directions. Thus, to find the impact from four neighbouring palms on the effective palm, the following four linear models were introduced, respectively.

$$
\begin{aligned}
Y_{i j}= & \mu+\tau_{i}+b_{j}+\beta_{1}\left(Y_{i,-1}+Y_{i, j+1}\right) / 2+\varepsilon_{i j} \\
Y_{i j}= & \mu+\tau_{i}+b_{j}+\beta_{2}(1) \\
Y_{i j}= & \mu+\tau_{i}+b_{j}+\beta_{3}\left(Y_{i, j-1}+Y_{i, j+1}\right) / 2+\beta_{4}\left(Y_{i-1, j}\right. \\
& \left.+Y_{i+1, j}\right) / 2+\varepsilon_{i j} \\
Y_{i j}= & \mu+\tau_{i}+b_{j}+\beta_{5}\left(Y_{i, j-1}+Y_{i, j+1}+Y_{i-1, j}+Y_{i+1, j}\right) / 4 \varepsilon_{i j}
\end{aligned}
$$

The models 1- 4 have four types of covariate derived from the yield of four neighbouring palms around an effective palm. In model (1) spatial effect for $Y_{\mathrm{ij}}$ was derived from the mean of two neighbouring palms along $\mathrm{E}-\mathrm{W}$ direction (i.e. mean value of $\mathrm{Y}_{\mathrm{i}-1, \mathrm{j}}$ and $\mathrm{Y}$ $\mathrm{i}+1, \mathrm{j}$.) and so it was included as a covariate into the model. If the value for $Y_{i-1, j}$

$\begin{array}{lll}\text { Block } 1 & \text { Block } 2 & \text { Block } 3\end{array}$

\begin{tabular}{|l|l|l|l|l|l|l|l|l|l|}
\hline$*$ & $*$ & $*$ & $*$ & $*$ & $*$ & $*$ & $*$ & $*$ & $*$ \\
\hline$*$ & $\bullet \mathrm{P}_{1} \mathrm{~T}_{3}$ & $\bullet$ & $*$ & $\bullet \mathrm{P}_{10} \mathrm{~T}_{4}$ & $\bullet$ & $*$ & $\bullet \mathrm{P}_{11} \mathrm{~T}_{5}$ & $\bullet$ & $*$ \\
\hline
\end{tabular}




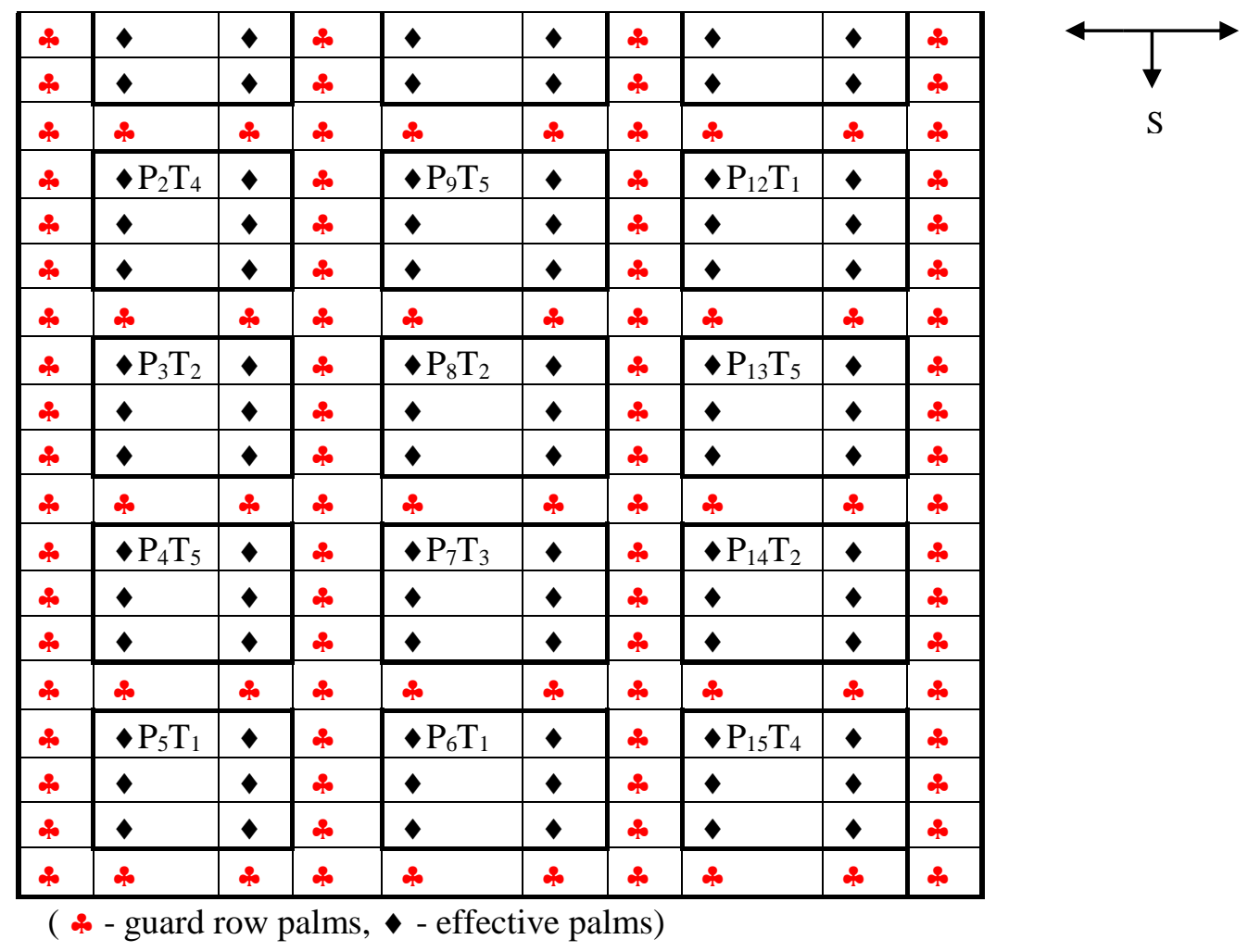

Fig. 1.Spatial position of the coconut palms of experiment 1

Block 1

Block 2

Block 3

\begin{tabular}{|c|c|c|c|c|c|c|c|c|c|c|c|c|c|c|c|c|c|c|}
\hline  & \& & \& & s & ه & As & \& & \% & As & \& & \& & \& & As & As & as & \& & as & s & \& \\
\hline$\Leftrightarrow$ & $\diamond$ & $\mathrm{T} 4$ &  & & $\diamond$ & \& & 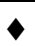 & T8 & $\diamond$ & & $\diamond$ & A & $\diamond$ & $\mathrm{T} 1$ & $\diamond$ & & $\diamond$ & \& \\
\hline \& & & 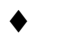 & & $\diamond$ & & \& & & $\diamond$ & & $\diamond$ & & \& & & $\bullet$ & & $\diamond$ & & \& \\
\hline \& & $\diamond$ & & 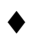 & & $\diamond$ & \& & 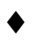 & & $\diamond$ & & $\diamond$ & 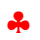 & $\diamond$ & & $\diamond$ & & $\diamond$ & \& \\
\hline
\end{tabular}




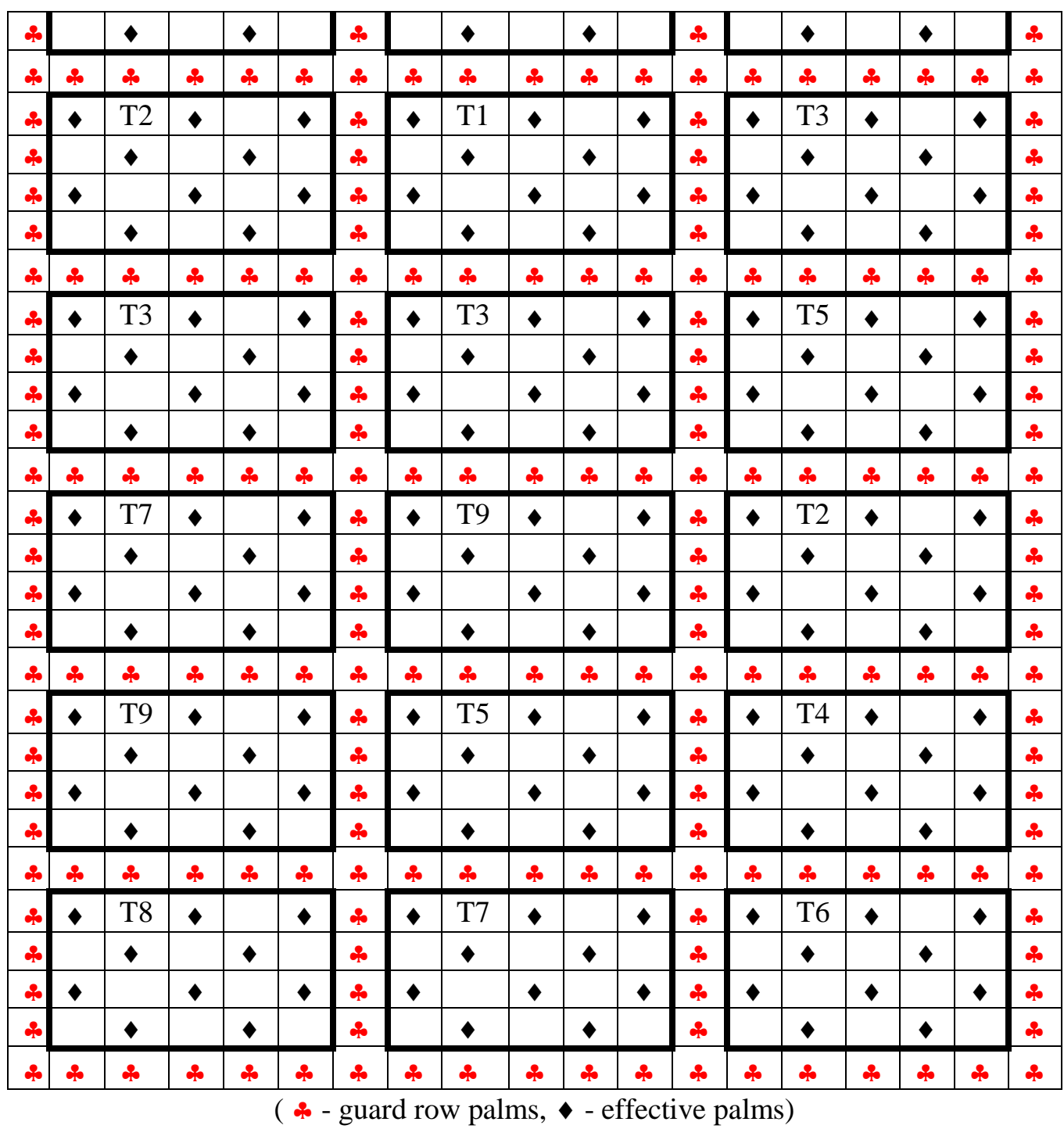

Fig. 2. Spatial position of the coconut palms of experiment 2

[T1 - V1F1, T2 - V2F1, T3 - V3F1 T4 - V1F2, T5 - V2F2, T6- V3F2, T7- V1F3, T8- V2F1, T9- V3F1]

Block 1

Block 2

Block 3

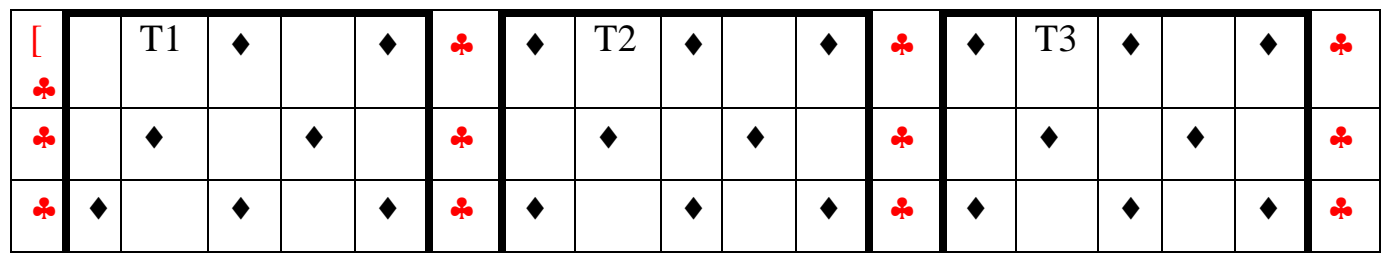




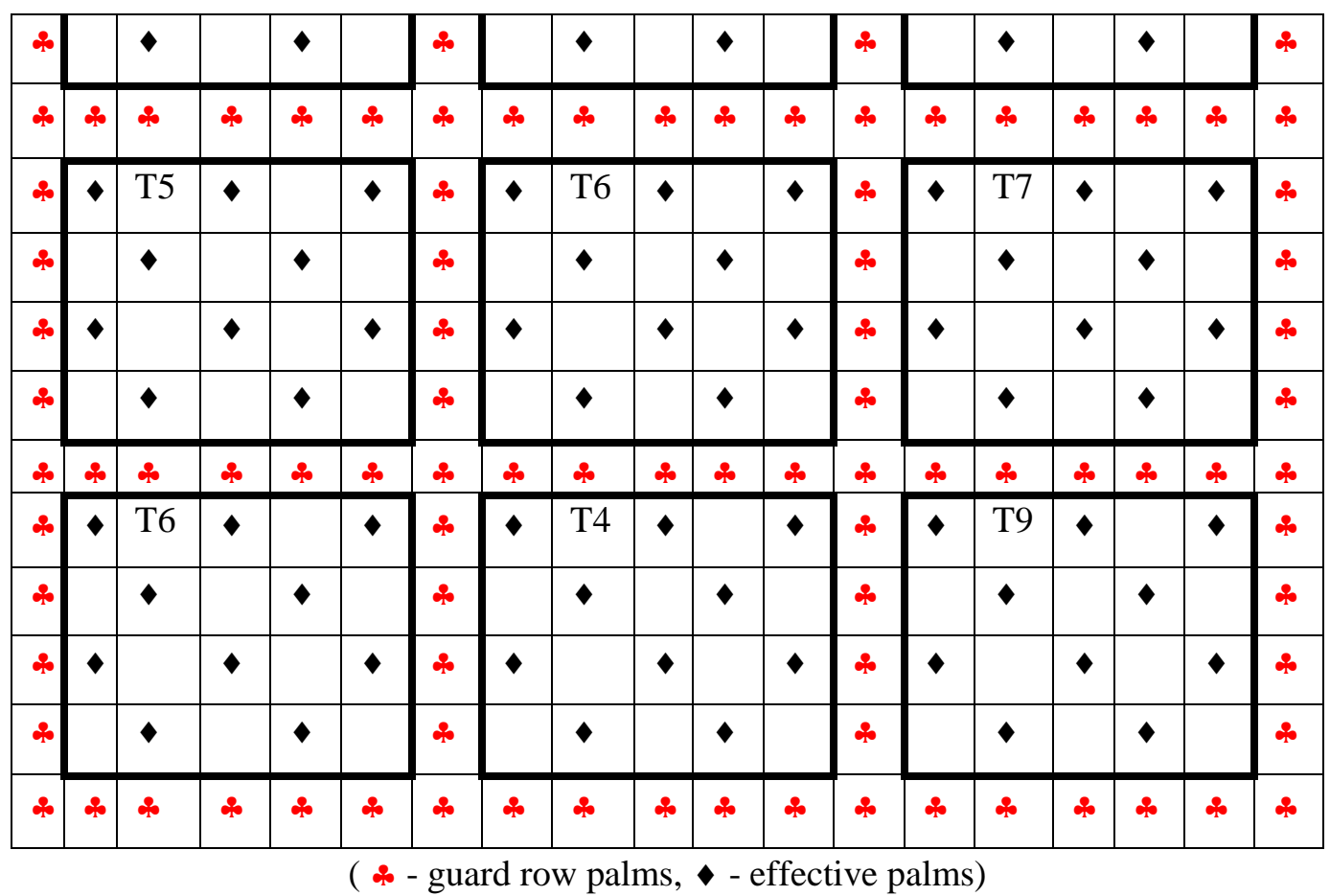

Fig. 2. Spatial position of the coconut palms of experiment 2 (Continued)

[T1 - V1F1, T2 - V2F1, T3 - V3F1 T4 - V1F2, T5 - V2F2, T6- V3F2, T7- V1F3, T8- V2F1, T9- V3F1]
*A1
a $\left(\mathrm{Y}_{\mathrm{i}, \mathrm{j}-1}\right)$
*A2
A $\left(\mathrm{Y}_{\mathrm{i}-1, \mathrm{j}}\right)$

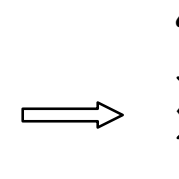
$\pi$
$\leftrightarrow \mathrm{A} 4$

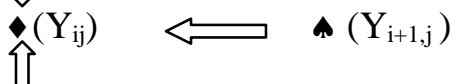
A $\left(\mathrm{Y}_{\mathrm{i}, \mathrm{j}+1}\right)$
*A3

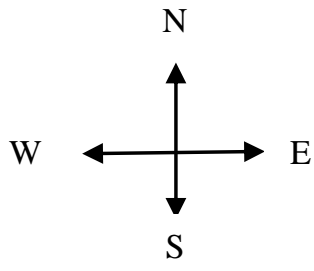

- - Middle tree; $\boldsymbol{\wedge}$ - neighbouring trees; $\$$ - corner trees

Fig. 3. The typical spatial layout of an effective coconut palm in an experiment

was missing or if $\mathrm{Y}_{\mathrm{ij}}$ came at the boundary of the experiment site (so that $\mathrm{Y}_{\mathrm{i}-1, \mathrm{j}}$ does not exist), then the covariate was taken as the yield of the remaining palm alone. Similarly in model 2, spatial effect was taken as by considering the mean of two neighbouring palms along N-S direction as a covariate. In model 3 spatial effect was considered by taking the mean of two neighbouring palms in $\mathrm{E}-\mathrm{W}$ and $\mathrm{N}-\mathrm{S}$ directions separately as two covariates. Finally in model 4 the mean of all four neighboring palms was taken as a covariate. The CVs and significance of treatments were evaluated by analyzing data separately for years in both experiments. This analysis was repeated by analyzing both experiments using repeated measure techniques. 
The percentage reduction in $\mathrm{CVs}$ of the adjusted data relative to the unadjusted data (without covariate) and repeated measures analysis were calculated. It should be pointed out that these models can be used when data are collected palm-wise in all palms including guard row palms as well, if guard rows are used.

\section{Results and discussions}

\section{Without covariate}

Results of the analysis by fitting the ANOVA of RCBD without covariate (i.e. ignoring neighbouring effort) is shown in Table 1.

Results in Table 1 indicates that no significant differences between treatments even with a difference between treatments is 17 nuts per palm per year in 1999. This could happen due to inefficient blocking. In this experiment predate has not been taken though the usefulness of pre-treat data as covariate has been suggested by Abeywardena (1970) for field experiments in coconut. However, very often the reason for this omission in field experiments is that the experimenter cannot wait for one year to start the experiment. In such occasions the method suggested by Peiris \& Thattil (1998) was used to remove the treatment and block effects from the first year data (post-treatment) so that such data can be used as covariate (pre-treat) for other years. However, the use of pre-treat data as a covariate does not account for the spatial effect of neighbouring palms on the effective palm due to fertilizer movement, root competition etc. and consequently in reducing local variability. Nevertheless, the ANCOVA was carried out

Table 1. Summary results of ANOVA of data set 1 for each year separately

\begin{tabular}{lccccccccc}
\hline Source of variation & \multicolumn{10}{c}{ Year } \\
\cline { 2 - 9 } & 91 & 92 & 93 & 94 & 95 & 96 & 97 & 98 & 99 \\
\hline Blocks & ns & ns & Ns & ns & ns & Ns & ns & ns & ns \\
Treatments & ns & ns & Ns & ns & ns & Ns & ns & ns & ns \\
\hline CV(\%) & 16.1 & 12.8 & 16.1 & 12.6 & 19.2 & 16.7 & 15.0 & 17.7 & 14.9 \\
MD (nuts/p/y) & 7.5 & 5.5 & 10.6 & 8.2 & 11.2 & 2.5 & 6.6 & 14.5 & 16.8 \\
\hline
\end{tabular}

using pre-treat data as covariate (Table 2) in order to compare impact of spatial effect.

Results in Table 2 indicate that the treatments were not significantly different for all the years and covariate was significant $(p<0.005)$ only for two years. Nevertheless CV was reduced substantially compared to being without the covariate model and it varied from $4 \%$ to $30 \%$ among years.

A similar trend was observed for data set 2 too when the analysis was carried out with and without the covariate. In data set 2 , the interaction between variety and fertilizer level was not significant, but only the varieties were significantly different. The covariate obtained by removing the treatment and block effects in 1998 data was not significant when 1999 data were analysed.

\section{Control of spatial effect}

\section{Data set 1}

When data were analysed by fitting the models 1- 4 separately (i.e. taking account for spatial effect in four different ways) the status of significance found for covariates and CVs are given in Tables 3 and 4 respectively.

Comparison of results in Tables 1 and 4 and Tables 2 and 4 indicate that all four models are superior to the normal RCBD model or the RCBD model with and without covariate. Results in Table 4 indicate that the models 2 and 3 are better than the models 1 and 4 with 
MD - Maximum difference between two treatments

Table 2. Summary of the results of ANCOVA taking pre-data as covariate for data set 1

\begin{tabular}{lcccccccc}
\hline \multirow{2}{*}{\multicolumn{1}{c}{ Source of variation }} & \multicolumn{8}{c}{ Year } \\
\cline { 2 - 9 } & 92 & 93 & 94 & 95 & 96 & 97 & 98 & 99 \\
\hline Treatments & $\mathrm{ns}$ & $\mathrm{ns}$ & $\mathrm{ns}$ & $\mathrm{ns}$ & $\mathrm{ns}$ & $\mathrm{ns}$ & $\mathrm{ns}$ & $\mathrm{ns}$ \\
Covariate & $*$ & $\mathrm{~ns}$ & $\mathrm{~ns}$ & $\mathrm{~ns}$ & $\mathrm{~ns}$ & $\mathrm{~ns}$ & $*$ & $\mathrm{~ns}$ \\
\hline $\mathrm{CV}(\%)$ & 8.9 & 7.1 & 12.6 & 16.5 & 15.1 & 13.6 & 13.7 & 13.9 \\
$\mathrm{MD}(\mathrm{nuts} / \mathrm{p} / \mathrm{y})$ & 10.7 & 6.1 & 7.6 & 13.5 & 5.8 & 10.0 & 16.6 & 21.9 \\
\hline
\end{tabular}

(MD - Maximum difference between two treatments; * significance at $p<0.05)$

Table 3. Status of significance of covariate by fitting models 1-4 for data set 1

\begin{tabular}{|c|c|c|c|c|c|c|c|c|c|c|}
\hline \multirow{2}{*}{$\begin{array}{l}\text { Spatia } \\
1\end{array}$} & \multirow[t]{2}{*}{ Covariate } & \multicolumn{9}{|c|}{ Year } \\
\hline & & 91 & 92 & 93 & 94 & 95 & 96 & 97 & 98 & 99 \\
\hline \multicolumn{11}{|l|}{ model } \\
\hline 1 & $(Y i, j-1+Y i, j+1) / 2$ & $*$ & $*$ & $*$ & $*$ & $*$ & $*$ & $*$ & $\mathrm{~ns}$ & $*$ \\
\hline 2 & $(Y i-1, j+Y i+1, j) / 2$ & $*$ & $*$ & $*$ & $*$ & $*$ & $*$ & $*$ & $*$ & $*$ \\
\hline \multirow[t]{2}{*}{3} & $(Y i, j-1+Y i, j+1) / 2$ and & $*$ & ns & ns & ns & Ns & ns & ns & $\mathrm{ns}$ & $\mathrm{ns}$ \\
\hline & $(Y i-1, j+Y i+1, j) / 2$ & $*$ & $*$ & $*$ & $*$ & $*$ & $*$ & $*$ & $*$ & $*$ \\
\hline 4 & $(Y i, j-1+Y i, j+1+Y i-1, j+i+1, j) / 4$ & $*$ & $*$ & $*$ & $*$ & $*$ & $*$ & $*$ & $*$ & $*$ \\
\hline
\end{tabular}

respect to $\mathrm{CV}$. The percentage reduction in $\mathrm{CV}$ under four models relative to RCBD without covariate is shown in Fig. 4.

It indicates that percentage reduction in $\mathrm{CV}$ is over $60 \%$ in models 2 and 3 and there is hardly any difference between those two models. In fact CVs under these two models were below $5 \%$. The covariates were significant $(p<0.05)$ for all years only in model 2 and model 4 . In model 3, only one of the covariates was significant for all years. Thus model 2 can be recommended as the best model to capture the spatial effect followed by model 3. In fact, Pearce and Moore (1976) pointed out that east-west adjustment is clearly more efficient than north-south adjustment, when long and narrow plots are used. It should be pointed out that lowest percentage reduction in CV was observed with model 4.

\section{Data set 2}

Data from experiment 2 were also analyzed as the first data set. The spatial covariates were 
significant for models 1,2 and 4 in both years (Table 5).

Fig. 5 indicates that all four models were superior compared to the ANOVA model of RCBD. With respect to percentage reduction in $\mathrm{CV}$ models 1 and 3 were far superior compared to models 2 and 4 (Fig. 5). The highest reduction in $\mathrm{CV}$ was found with models 1 and 3. However, with model 3 spatial covariate (adjustment from both directions) were not significant. Thus the best model to capture spatial effect is model 1 indicating adjustment is more efficient in N-S direction in experiment 2 .

\section{Use of repeated measures analysis}

Since in both experiments measurements were taken from the same unit over the years, the effect of spatial neighbouring adjustment was studied by analyzing data using repeated measure techniques too. The CVs obtained for unadjusted (without spatial effect) and adjusted data (by fitting four spatial models) for both experiments are shown in Table 6.

Results in Table 6 indicate that there is not much of a difference in the percentage reduction between model 3 and 2 in experiment 1 and between model 3 and 1 in experiment 2 . However, it can be confirmed that model 3 is the best to capture the spatial effect in both experiments when data were analyzed using repeated measures techniques. That is, when data are analyzed using repeated measure techniques, the most efficient model to capture spatial effect is the use of all four neighboring palms.

\section{Conclusion}

The study confirmed that spatial adjustment using yield in neighboring palms is a good techniques in improving the precision of field experiments of coconut. Results confirmed all four spatial models are superior relative to the RCBD model without covariate or with preyield as covariate irrespective of the type of experiments and whether data are analyzed separately for years or all data simultaneously using repeated measure analysis. Of the four models, spatial adjustment either N-S or E-W is superior compared to fitting RCBD models, when the data are analyzed separately for years. The direction may depend on the relation of row direction to the east-west track of the sun, and the type of crop. The adjustment of data for both row and column effects separately is recommended for field experiments in coconut when data are analyzed using repeated measures techniques. It is recommended to apply these models to other types of tree crop experimentation, where measurements are taken on trees separately.

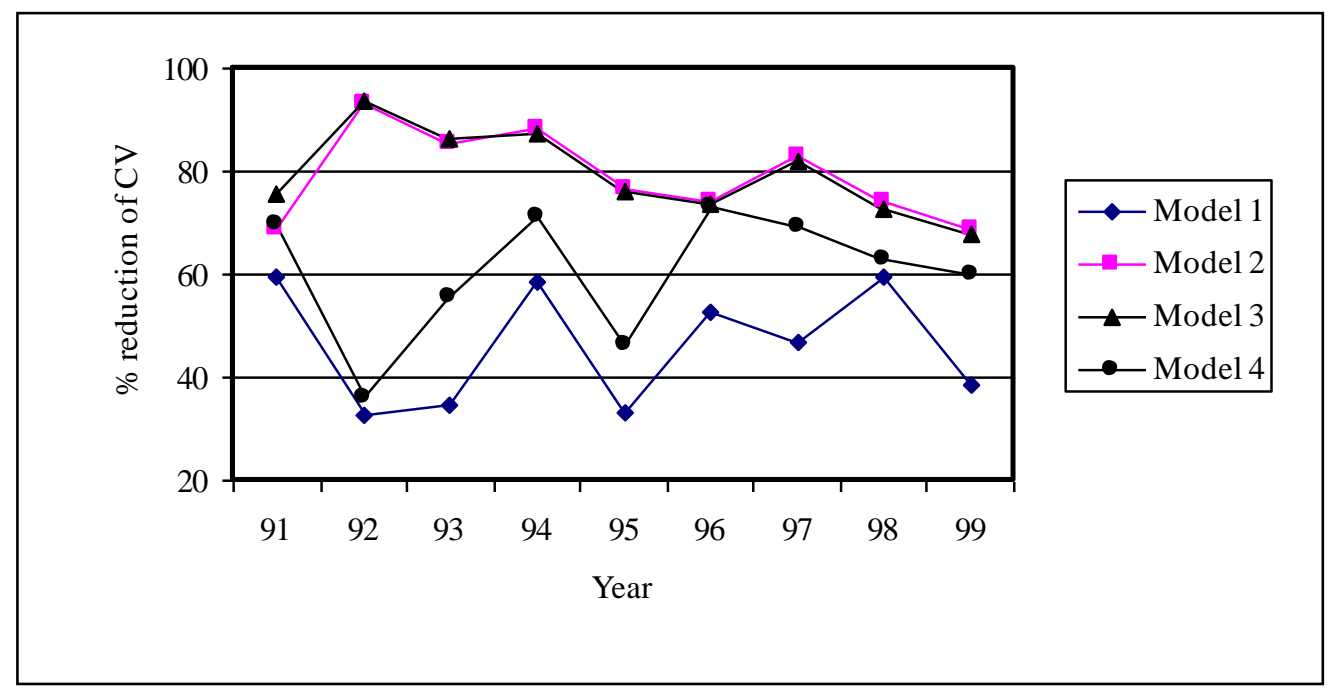


Fig. 4. Percentage of reduction in $\mathrm{CV}$ with spatial covariates by fitting models 1-4 relative to ANOVA model of RCBD in data set 1

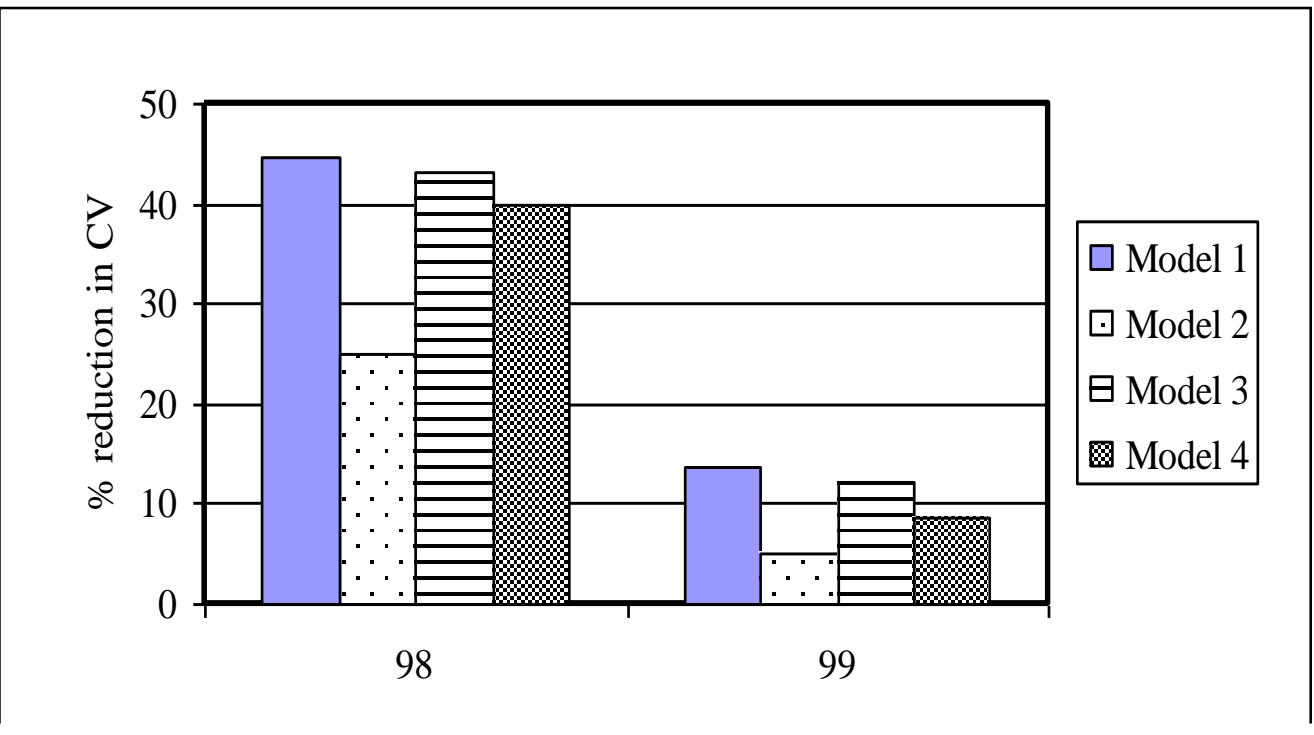

Fig. 5. Percentage of reduction in $\mathrm{CV}$ with spatial covariates by fitting models 1-4 relative to ANOVA model of RCBD in data set 2

Table 4. CVs by fitting the models 1- 4 for data set 1

\begin{tabular}{lccccccccc}
\hline Spatial & \multicolumn{7}{c}{ CV } \\
\cline { 2 - 9 } & 91 & 92 & 93 & 94 & 95 & 96 & 97 & 98 & 99 \\
\hline Model 1 & 6.5 & 8.6 & 6.6 & 5.2 & 12.8 & 7.9 & 8.3 & 7.2 & 8.9 \\
Model 2 & 5.0 & 0.9 & 1.5 & 1.5 & 4.5 & 4.3 & 2.7 & 4.6 & 4.5 \\
Model 3 & 3.9 & 0.8 & 1.4 & 1.6 & 4.6 & 4.4 & 2.8 & 4.8 & 4.7 \\
Model 4 & 4.9 & 8.2 & 4.5 & 3.6 & 10.3 & 4.5 & 4.8 & 6.6 & 5.8 \\
\hline
\end{tabular}

Table 5. Status of significance of covariate by fitting models 1-4 for data set 2

\begin{tabular}{llll}
\hline Spatial model & Covariate & 98 & 99 \\
\hline
\end{tabular}




\begin{tabular}{clcc}
\hline 1 & $(\mathrm{Yi}, \mathrm{j}-1+\mathrm{Yi}, \mathrm{j}+1) / 2$ & $*$ & $*$ \\
2 & $(\mathrm{Yi}-1, \mathrm{j}+\mathrm{Yi}+1, \mathrm{j}) / 2$ & $*$ & $*$ \\
3 & $(\mathrm{Yi}, \mathrm{j}-1+\mathrm{Yi}, \mathrm{j}+1) / 2$ and & $*$ & $\mathrm{~ns}$ \\
& $(\mathrm{Yi}-1, \mathrm{j}+\mathrm{Yi}+1, \mathrm{j}) / 2$ & $*$ & $*$ \\
4 & $(\mathrm{Yi}, \mathrm{j}-1+\mathrm{Yi}, \mathrm{j}+1+\mathrm{Yi}-1, \mathrm{j}+\mathrm{Yi}+1, \mathrm{j}) / 4$ & $*$ \\
\hline
\end{tabular}

Table 6. CVs with spatial effect and without spatial effect along with percentage reduction compared to without spatial effect under four spatial models after using repeated measure techniques for data sets 1 and 2

\begin{tabular}{|c|c|c|c|c|c|}
\hline & \multirow{2}{*}{$\begin{array}{l}\text { CV without } \\
\text { spatial effect }\end{array}$} & \multicolumn{4}{|c|}{ CV with spatial effect with } \\
\hline & & Model 1 & Model 2 & Model 3 & Model 4 \\
\hline \multicolumn{6}{|l|}{ Data set 1} \\
\hline $\mathrm{CV}(\%)$ & 13.3 & 9.0 & 7.1 & 6.5 & 8.4 \\
\hline$\%$ reduction & & 32.3 & 46.6 & 51.2 & 36.8 \\
\hline \multicolumn{6}{|l|}{ Data set 2} \\
\hline $\mathrm{CV}(\%)$ & 15.0 & 9.3 & 10.2 & 9.1 & 10.6 \\
\hline$\%$ reduction & & 38.0 & 32.8 & 39.3 & 29.3 \\
\hline
\end{tabular}

\section{Acknowledgement}

A shorter version of this paper was presented at the Biometric Conference in Germany in 2002. We are grateful to colleagues from Soils \& Plant Nutrition Division and Genetics \& Plant Breeding Division of CRI for providing data. Our sincerely thank to Udula of Biometry Division, CRI for editing the paper.

\section{References}

Abeywardena, V. 1970. The Efficiency of PreExperimental Yield in the calibration of Coconut Experiments. Ceylon Cocon. Quart, 21: 85-91.

Besag, J. \& Kempton, R. 1986. Statistical analysis of field experiments using neighbouring plots. Biometrics, 42: 231-251.
CRI. 2000. Annual report of the Coconut Research Institute of Sri Lanka.

Gomez, A. K. \&d Gomez, A. A. 1984. Statistical Procedures for Agricultural Research. A Wiley -Inter Science Publication, America.

Kempton, R. A. \& Howes, C. W. 1981. The use of neighbouring plots values in the analysis of variety trials. Applied statistics, 30(1):5970.

Liyanage, M. De S. 1999. A Guide to scientific cultivation and management of coconut. Hitech Prints, Nugegoda.

Mead, R. 1988. The design of experiments. A Wiley -Inter Science Publication, America. 
Pearce, S. C. 1976. Field experimentation with fruit trees and other perennial plants. Slough, $\mathrm{CAB}$.

Pearce, S. C. \& Moore, C. S. 1976. Reduction of Experimental Error in Perennial Crops, Using Adjustment by Neighbouring Plots. Experimental Agriculture, 12: 267-272.

Peiris, T. S. G., Hansen, J. W. \& Lareef, Zubair 2007. Use of Seasonal Climate Information to Predict Coconut Production in Sri Lanka. Int. J of Climatology (in Press)
Peiris, T. S. G. \& Thattil, R. O. 1997. Alternative methods to determine optimal plot size for perennial crops. Cocos, 12: 4454.

Vollmann, J., Buerstmayr, H. \& Ruckenbauer, P., 1995. Efficient Control of Spatial Variation in Yield Trials Using Neighbour Plot Residuals. Experimental agriculture, 32: 185-197. 